Accepted Manuscript of the article published in Social Epistemology,

https://doi.org/10.1080/02691728.2020.1839810. Please use the published version for quotations and page numbers.

\title{
Genocide Denial as Testimonial Oppression
}

\author{
Melanie Altanian (University College Dublin)
}

\begin{abstract}
This article offers an argument of genocide denial as an injustice perpetrated not only against direct victims and survivors of genocide, but also against future members of the victim group. In particular, I argue that in cases of persistent and systematic denial, i.e. denialism, it perpetrates an epistemic injustice against them: testimonial oppression. First, I offer an account of testimonial oppression and introduce Kristie Dotson's notion of testimonial smothering as one form of testimonial oppression, a mechanism of coerced silencing particularly pertinent to genocide denialism. Secondly, I turn to the epistemology of genocide denialism and, using the example of Turkey's denialism of the Armenian genocide, show how it presents what Linda Martín Alcoff calls a substantive practice of ignorance. Thirdly, I apply these considerations to individual practices of genocide denial and analyse the particular characteristics of testimony on genocide, the speaker vulnerabilities involved and the conditions under which hearers will reliably fail to meet the dependencies of a speaker testifying to genocide. Finally, I explore the harms that testimonial oppression perpetrates on members of the victim group, insofar as it systematically deprives them of epistemic recognition.
\end{abstract}

Keywords: Genocide denial; testimonial oppression; substantive ignorance; silencing; epistemic recognition

\section{I - Introduction}

Genocide denial is often referred to as the 'final stage of genocide'. However, to speak of denial as belonging conceptually to genocide obscures that apologism, legitimation and denial are already present prior to and during the crime. With these practices, perpetrators prepare the ideological grounds to justify their actions and policies and thereby also provide the basis for denialism in the long run. In this article, I focus on the 
practice of genocide denial itself in order to bring to light how it constitutes a further injustice perpetrated against the (former) victim group. Addressing the very practice of genocide denial will help us identify it as an intergenerational, sustainable discrimination policy that gives future members of the victim group continued reasons to feel threatened. ${ }^{1}$ This further enables us to distinguish responsibility for genocide from responsibility for its denial, a distinction that is particularly important from the point of view of intergenerational justice.

Such an inquiry is suggested by systematic, institutionalized and structurally entrenched cases of genocide denial, such as Turkey’s ongoing denialism of the Armenian genocide. Here, succeeding governments are not only reactively, but actively and wilfully engaging in genocide denialism through argumentative and narrative, factual and normative distortions, many of which are not easily discernible as genocide legitimation or racist hate speech. This warrants an in-depth investigation of the injustice of genocide denialism at the intersection of ethics and epistemology. More specifically, this article aims to identify how genocide denialism constitutes an epistemic injustice. I focus here particularly on how conditions of genocide denialism give rise to individual practices of denial, i.e., pernicious patterns of communication that amount to testimonial oppression. In what follows, I first offer an account of testimonial oppression and introduce Dotson’s (2011) notion of testimonial smothering as one form of testimonial oppression particularly pertinent to genocide denialism. I then turn to the epistemology of genocide denialism and, using the example of Turkey's denialism of the Armenian genocide, show how it presents what Alcoff (2007) calls a substantive practice of ignorance. Against this background, I analyse individual (i.e. interpersonal) practices of genocide denial, that is, the particular characteristics of testimony on genocide, the speaker vulnerabilities involved and the conditions under 
which hearers will reliably fail to meet the dependencies of a speaker testifying to genocide. Finally, I explore the harms of testimonial oppression perpetrated against members of the former victim group, insofar as it systematically deprives them of epistemic recognition.

\section{II - Testimonial Oppression}

Oppression is a normative concept that names a particular social injustice. I adopt Cudd's empirically informed, univocal concept of oppression as

institutionally structured harm perpetrated on groups by other groups using direct and indirect material and psychological forces that violate justice. ...These forces work in part by coercing the oppressed to act in ways that further their own oppression. (Cudd 2006, 26)

Cudd identifies four necessary and sufficient conditions for oppression: There is a harm that comes out of an institutional practice ${ }^{2}$; the harm is perpetrated through a social institution or practice on a social group whose identity exists apart from the oppressive harm $^{3}$; there is another (privileged) social group that benefits from this institutional practice; and there is unjustified coercion or force that brings about the harm $(2006,25)$. Against this background, I define testimonial oppression as unjustified epistemic coercion through (institutional) practices that bring about distinctly epistemic and other harms insofar as testifiers occupy a specific, not only epistemically, but also ethically relevant status: the status of a knower (or an epistemic agent more generally). Knower is therefore also an ethical concept that can be grasped only against the background of what it means to live a flourishing human life where testifying is regarded as a capacity of essential human value (e.g., Congdon 2018; Fricker 2007, 44, 2015). The primary harm of testimonial oppression lies not merely in being disrespected as a full human subject on the basis of institutional and structural discrimination, but in thereby being 
stymied in one’s ability to exercise a valuable human capacity, that is, (moral-) epistemic agency. Furthermore, the harm is perpetrated against a particular social group to the (purported) benefit of another social group.

To understand how a speaker can be harmed in testimonial practice, we have to take into account her relational vulnerabilities in testifying; what she (justifiably) trusts the hearer for and what it means for this trust to be betrayed. In particular, speakers trust hearers mainly for ‘recognitional epistemic goods’ (Dormandy 2020, 247), consisting in the right response to a person's epistemic agency or to their status as a knower. Thus, testimonial oppression refers to conditions and practices that persistently and systematically deprive speakers of such recognitional epistemic goods. According to Dotson (2011, 244), such testimonial oppression can take, among others, the form of 'testimonial smothering', which occurs when 'the speaker perceives one’s immediate audience as unwilling or unable to gain the appropriate uptake of proffered testimony' ${ }^{4}$ She identifies three, usually interrelated circumstances that routinely give rise to testimonial smothering: i) the content of the testimony is unsafe and risky, ii) the audience demonstrates testimonial incompetence to the speaker with respect to the content of the testimony, and iii) testimonial incompetence follows from, or appears to follow from, pernicious ignorance. Under such circumstances, it is likely that speakers will be coerced to silence themselves, hence testimonially smothered.

The content of testimony is unsafe and risky when it leads or contributes to the ‘formation of false beliefs that can cause social, political, and/or material harm' (Dotson 2011, 244). As an illustration, Dotson refers to Kimberlé Crenshaw’s (1991) analysis of women-of-color silencing themselves as regards experiences of domestic violence committed by their male, non-white community members, because it might reinforce and corroborate the widespread, racist stereotype of the 'violent black male'. Their 
societal context coerces women-of-color to silence themselves on this matter because it is imbued with racist stereotypes and misunderstandings that make testimony on domestic violence risky, insofar as it may corroborate such misunderstandings and endanger non-white communities even further. (Dotson 2011, 244-245) This relates to the testimonial incompetence of an audience, i.e., 'the failure of an audience to demonstrate to the speaker that she/he will find proffered testimony accurately intelligible' (245). Testimony will be accurately intelligible to an audience if it is clearly comprehensible and defeasibly intelligible, which includes awareness and recognition of epistemic limits, gaps, inaccuracies or uncertainties in one’s comprehension. Accordingly, a speaker trusts an audience to exercise testimonial competence, meaning 'to do what it takes to hear what she intends to communicate' (Dormandy 2020, 256). This can also involve trusting the audience to respect any emotional or practical risks that a speaker might expose herself to, namely when testifying to 'experiences of marginalization to someone who is likely to have trouble relating, especially if their shared conceptual framework cannot easily bridge their disparate backgrounds’ (257). In turn, demonstrating testimonial incompetence will coerce potential speakers to silence themselves with respect to some domain of knowledge. The cultivation of such testimonial incompetence can depend on how a certain subject matter is framed in a society's public discourse. For example, Cassandra Byers Harvin illustrates this when she confesses that she has been made to 'avoid speaking candidly about race with her colleagues as a result of the "hurt feelings and surprise and defensiveness” that her audience may take on during such conversations' (Harvin 1996, 16, as quoted in Dotson 2011, 247). Harvin describes one encounter in a public library with a white woman, “early-50s-looking” who asks Harvin what she is working on: 
Harvin responds by indicating she is researching "raising black sons in this society". The white woman promptly asks, "How is that any different from raising white sons?" Harvin notes that it is not only the question that is problematic, as it indicates a kind of lack of awareness of racial struggles in the United States, but also the tone of the question that indicated the white woman believed that Harvin was "making something out of nothing”. (Ibid., emphasis added)

The immediate question, "How is that any different from raising white sons?" as well as the tone in which it was asked represents an unnecessarily sceptical question 'that can operate to effectively negate the experiential reality of many people of color' (Dotson 2011, 247). Such responses are likely the result of pernicious situated ignorance. One could argue that the white woman is ignorant because she was never in a position to raise black sons in the U.S.; hence she lacks a socially situated experience. However, in addition, she seems ignorant of her own situated unawareness-likely due to further protective, cognitive mechanisms akin to what Medina calls privileged ignorance: her not needing to know about her own unawareness (viz. 'epistemic laziness', Medina 2013, 33). After all, she could potentially demonstrate testimonial competence despite not sharing the same experiential or lived reality of how it is to raise black sons in the U.S. She could still accept or be justified in accepting and trusting the black woman's insight and therefore acknowledge this as a conversation one should have insofar as one can gain a better understanding of how racism operates in one's society. This is why such a rhetorical or 'pseudo'-sceptical response can invalidate her as a knower and epistemic agent more generally. ${ }^{5}$ Moreover, situated ignorance likely renders hearers unable to acknowledge any emotional or practical risks that speakers expose themselves to when testifying to experiences of marginalization. They may thereby, intentionally or unintentionally, perpetuate the oppression of the marginalized. I argue that a similar practice of silencing can be observed in the case of genocide denialism, insofar as it 
generates pernicious situated ignorance that cultivates testimonial incompetence specifically on the subject matter of genocide and makes testimony on genocide unsafe and risky, thus paving the way for testimonial smothering.

\section{III - Genocide Denialism: Generating Pernicious Reliable Ignorance}

Denialism refers to the larger, orchestrated, ideological, political or cultural pattern of denial; it tends to include 'an agenda not necessarily outspoken, a world view, argumentative traditions and structures, as well as similar motives and motivations' (Karlsson 2015, 38). Here, I am concerned with genocide denialism as a historically rooted practice that authorizes, justifies and imposes a pernicious set of beliefs and understandings by: maintaining historically entrenched prejudices against the former victim group, misrepresenting social reality, distorting historical facts about genocide as well as the social, moral and epistemic norms that ought to guide successful inquiry in this domain. On this basis, denial and disputation rather than recognition of genocide will appear to be the right thing to do from the perspective of both morality and epistemology. I shall illustrate this phenomenon by analysing Turkey’s denialism of the Armenian genocide, in particular: the historically entrenched portrayal of Armenians as murderous, domestic threats in the founding narrative of the Turkish Republic, as well as normative distortions of collective memory through the state policy of just memory. ${ }^{6}$ Note that genocide denialism does not merely consist in disputing whether the legal term of genocide can be applied to the historical injustice retrospectively. Rather, it consists more generally in challenging whether Armenians have suffered a group-based injustice, a type of injustice we have afterwards come to understand as a crime called genocide. However we come to define genocide, denialism aims at distorting normativity and social reality in a way so as to exclude the Armenian experience from this definition of a particular crime against humanity. 
Mustafa Kemal was the commander-in-chief of the Nationalist Army in the Turkish war of independence and the first president of the Turkish Republic. Given his authority and, in fact, authoritarianism in narrating Turkish history, he has significantly shaped the history of modern Turkey and (Kemalist-) Turkish national identity until today. This includes his various speeches from 1917 onwards, in which he repeatedly puts rhetorical emphasis on the suffering and oppression of Turks, and Armenians murdering Turks during his war of independence, which has led to chronological confusions used as retrospective justification for the Armenian genocide to this day. More specifically, in his domestic policy, Kemal emphasizes his concern about the emergence of an independent Armenia in the East and an Armenian invasion, which would make organized national resistance necessary. Even more so, he writes, because “"the Armenian cause is considered to be legitimate by both the western nations and the Russian nation”, since Armenians had been portrayed to the West and to the United States as "the oppressed"' (as quoted in Ulgen 2010, 377-378). Neglecting the legacy of pogroms and oppression that Ottoman Armenians have experienced and their destruction and expulsion from their homeland under Young Turk rule, he in fact reverses the claim and highlights the atrocities committed by returning Armenians during his war of independence:

In numerous telegrams and other communications, especially between mid-1919 and late 1920 - that is, until the defeat of [the First Republic of] Armenia - Kemal described the atrocities Muslims suffered around and beyond the eastern border as "savagery and murder” ..., “destruction and extermination” ..., “extermination one by one” ..., "massacre” ..., "policy of Muslim massacre and extermination” ..., and “oppression and atrocity/carnage”. (Ulgen 2010, 379)

This rhetoric is repeated in his famous speech from 1927, Nutuk. This speech 
displays almost all the memory tropes still in currency in contemporary Turkey: Armenians and the spirit of revenge; Armenians who completely destroyed old Muslim towns; Armenians murdering and annihilating thousands of innocent women and children; Armenians, the perpetrators of savagery unique in history (388).

Kemal thereby reframes in particular the Battle of Maraş by assimilating Armenians into the enemy of the French occupying forces, obscuring the murder of thousands of Armenians (including refugees who were repatriated following the genocide) and calling the "Armenian and Greek army the "old murderers" let loose by the imperialists on the Muslims in Anatolia, "the home of Islam since the time of the Seljuk Turks”' (as quoted in Ulgen 2010, 380). This illustrates the continuity of the portrayal of Armenians (and other Ottoman Christians) as ‘puppets of imperialists' already in place prior to and during the genocide of 1915-16.

Another strategy of genocide denialism is the distortion of normativity at the level of its social articulation (see Pauer-Studer and Velleman 2011). Under the guise of humanism and sincere ethical concern, this strategy suggests getting rid of 'political considerations of victimhood' and controversial terms such as genocide, in order to interpret what happened as a 'general tragedy' that engulfed all the people of the Empire. This has found its way into official statements of condolence by government officials, as for example illustrated by (then Prime Minister) Erdoğan’s statement from April 23, 2014:

It is indisputable that the last years of the Ottoman Empire were a difficult period, full of suffering for Turkish, Kurdish, Arab, Armenian and millions of other Ottoman citizens, regardless of their religion or ethnic origin. Any conscientious, fair and humanistic approach to these issues requires an understanding of all the sufferings endured in this period, without discriminating as to religion or ethnicity. ${ }^{7}$ 
The Turkish government's official term for this new approach or policy of remembrance is that of just memory, as employed later in the statement: 'The incidents of the First World War are our shared pain. To evaluate this painful period of history through a perspective of just memory is a humane and scholarly responsibility.' This statement was given one day prior to the official, annual commemoration of the Armenian genocide and it is not only used to entrench denialism but to further discredit claims to genocide recognition, by framing them in a negative, threatening light:

In Turkey, expressing different opinions and thoughts freely on the events of 1915 is the requirement of a pluralistic perspective as well as of a culture of democracy and modernity. Some may perceive this climate of freedom in Turkey as an opportunity to express accusatory, offensive and even provocative assertions and allegations.

Note that by insisting that 'all have suffered', the policy of just memory leads to the contradictory conclusion that actual Armenian suffering ought to be silenced. Moreover, this pseudo-humanistic approach neutralizes and equates the experiences of Armenians during the late Ottoman period with the Muslim-Turkish citizens of the Empire, 'whose ideology was habitually instated with the nationalist Union and Progress government' (Aybak 2016, 135). Because of this, the insistence of Armenians on having their own experience of a particular injustice acknowledged instead of having it dissolved in some abstract, global memory of shared suffering is seen as exclusionary and reactionary stubbornness. Their claim to genocide recognition is reinterpreted and discredited as a sign of radical Armenian nationalism and terrorism, anti-Turkish provocation and an unwillingness to have peaceful relations with Turks. This polarization is further entrenched by the following excerpt of an 'overview' given on the website of Turkey’s Ministry of Foreign Affairs: 
The Armenian view of history, however, selects the Armenian suffering, embellishes it in several ways and presents it as a genocide - a crime defined in international law - perpetrated by Turks against Armenians. The acceptance of this version by others has become the national objective for Armenia and the radical groups within the Armenian Diaspora. [...] During the 1970s and onwards, such nationalistic zeal led to a terror campaign that took the lives of 31 Turkish diplomats and their family members, as well as 43 people from Turkish and other nationalities, and wounded many. ${ }^{8}$

Even though the Armenian genocide is framed as an 'ongoing matter of legitimate scholarly debate', the basic premise that Armenians suffered a particular injustice is categorically denied. Such statements implicitly entail the commitment to present history in a way so as to interpret away that Armenians, as an inferior group, have suffered injustice at the hands of the dominant and dominating group defined as Turks. As succinctly analysed by Theriault, this leads to flawed frameworks for conceptualizing Armenian-Turkish relations that 'treat Armenians and Turks as two parties to a conflict or disagreement that can enter into some form of negotiative or dialogue process as roughly equal partners’ (2009, 91). It obscures that the genocide was the middle phase of an overarching relationship of Turkish domination of Armenians. Considered this way, genocide emerged from within a dominating institutional context that has already attained legitimacy, making ongoing genocide denialism a means to maintaining such domination.

What epistemological insights can we draw from this? The denialism investigated here does not just refer to the telling of known falsities or withholding of (known) truth with the intention to deceive and mislead others. Rather, systematic efforts are taken to distort evidence and create a new, wholly opposite understanding that consists not merely of a lack of true beliefs about the Armenian genocide, but a motivated establishment and imposition of an alternative, distorted reality or world- 
view. It can be upheld by psychological mechanisms such as wishful thinking and selfdefence that keep one from seeking the truth in the first place - hence constituting ‘willful ignorance’ (see e.g. Pohlhaus Jr. 2012, 731-733). However, denialism also presents an epistemic practice that produces conditions under which it becomes difficult or at least risky for affected individuals to form proper knowledge and understanding, even if they are generally open-minded. Against this background, genocide denial becomes a complex phenomenon on the individual cognitive psychological, sociopolitical as well as normative level, presenting what Alcoff (2007) calls a substantive practice of ignorance. On this account, ignorance goes beyond the propositional level and involves the agent's epistemic behaviour more generally, including the attitudes (or norms and policies) that guide that behaviour. We can explain such ignorant agency by taking into account structural conditions that produce identities, social locations and modes of belief formation, which in some cases, can become epistemically disadvantageous or defective (Ibid., 40).

From a social-political point of view, genocide denialism functions to maintain a system of (in the case at hand, ethnonational) domination. To evaluate genocide denialism through the framework of substantive ignorance makes it possible to see how this is also epistemically relevant in an immediate sense, in that it gives rise to particular cognitive norms that constitute perniciously ignorant epistemic agents. On the one hand, there is individual denial, which are conscious or unconscious cognitive mechanisms through which individuals engage in practices of denial. On the other hand, there is the institutional and structural dimension of denialism that nurtures and informs but also goes beyond individual denial. Both levels and their interrelation have to be considered for an analysis of how genocide denialism itself constitutes injustice, or as I argue, testimonial oppression. Testimonial oppression is not perpetrated merely through 
isolated acts of denial owing to individual biases or psychological defence mechanisms. Rather, it is embedded in particular institutional background conditions and structures (of domination) that are sustained through individual repetition and habit. Thus, testimonial oppression tracks patterns of pernicious epistemic behaviour that maintain unjust social relations over time. In the following section, I demonstrate how such conditions render communicative encounters on matters of genocide persistently dysfunctional by giving rise to testimonial smothering. For this purpose, I first discuss some of the characteristics of the testimony we are concerned with and spell out the particular relationship between speakers and hearers when it comes to genocide-related testimony under non-ideal conditions of genocide denialism.

\section{IV - Genocide Denial: Speaker Vulnerabilities and Testimonial Incompetence}

The conditions illustrated in the previous section have serious long-term effects on the social imagination of the Armenian people in Turkey and beyond, but also on how hearers comprehend, interpret and receive their testimony in relation to past genocide, leaving testifiers vulnerable to unapt and epistemically depriving responses. For my following analysis, I am not primarily interested in racist hate speech that explicitly justifies genocide or incites violence against members of the former victim group. Rather, my concern is with every day, possibly 'naïve' denial that can take various forms of epistemic resistance to and discredit of testimony on genocide, where such resistance is owed to more pervasive ignorance. I am therefore using the term denial in a broad sense, also covering disputation and (pseudo-) scepticism. Consider the following encounters narrated by the Argentinian-Armenian artist Silvina Der-Meguerditchian:

Today I spoke to D., a Turkish student [...] I asked if she wanted to be in my collection of Turkish/Armenian encounters. [...] When I described the project, I told 
her where my grandparents came from and that they had survived the genocide. She looked a bit uncomfortable and said: "We don't know whether that happened or not." [...] I wanted to cry... This student had been so nice to me and so friendly and recent experiences had been so positive that I felt especially hurt when she said: “We don't know whether that happened or not.” [...] How is one to bear the fact that someone so young and warm and friendly says she doesn't know if something that shaped and defines one’s whole existence happened or not? (Der-Meguerditchian 2011, 24)

As soon as we were introduced, I felt the need to tell T. that we came from the same place or had something in common. I didn’t say that to provoke him. I think I was very naïve. I told him that my grandparents were also from Turkey and had had to leave, that they were survivors of the genocide. "Genocide?" He said, "What genocide?” THAT NEVER HAPPENED. The piece of bread I was chewing stuck in my throat. Without saying a word, I stood up and left. [...] I think this experience rather clearly marked a long pause in my attempt to re-establish some form of relationship with Turks. (8)

Both encounters left Der-Meguerditchian disappointed or even betrayed, hurt, and speechless. I take these to be fairly typical or common examples of everyday denial experienced by Armenians in Turkey and abroad. Even without taking the context of genocide denialism into account, they present rather strange kinds of conversations, and I doubt that we would normally expect responses like this to the kind of information offered, particularly in the student's case given their positive and friendly relationship. ${ }^{9}$ I suggest that these encounters present cases of miscommunication, in which the hearer takes the speaker's words to mean something that she did not intend to convey and which provokes a defensive sceptical response on behalf of the hearer. Indeed, as demonstrated in the previous section, the term genocide can carry particular, contextually established associations through which its expression is misinterpreted as an attempt to convey inappropriate accusations, provocations and immoral sentiments towards the socially 
dominant group. ${ }^{10}$ This can at least partially explain why her testimony prompts such arguably inadequate and hurtful responses.

To understand the normative implications of such testimonial encounters and experiences, I suggest an account of testimony as an act of communication, whereby a speaker intends to convey particular information to an audience and, by conveying the information, expects a certain response from the hearer, including recognition of how the speaker intends the information. That is, the hearer is expected to exercise testimonial competence as well as respect any emotional or practical risks to which testimony might expose the speaker. I argue that genocide denialism systematically hampers the ability of hearers to fulfil these demands, thereby instituting 'a harmful practice of silencing' (Dotson 2011, 241). According to Dotson, a practice of silencing-as opposed to instances of silencing - 'concerns a repetitive, reliable occurrence of an audience failing to meet the dependencies of a speaker that finds its origin in a more pervasive ignorance' (Ibid). The way in which the Turkish societal context frames the 'Armenian genocide debate' not only renders testimony on the Armenian genocide misunderstandable, but also creates the risk that it reinforces negative identity prejudice. Given that testimony on the Armenian genocide is characterized as an accusatory, baseless expression of radical Armenian nationalism, Turcophobia or Islamophobia, it becomes unsafe and risky testimony insofar as hearers might take it as evidence for their perceptions of Armenians as agitators and provocateurs. This likely coerces the latter to silence themselves in order not to risk the further endangerment of their community.

Of course, the term genocide is evaluative and, particularly in its legal use, includes an accusatory element. Such testimony can prompt defensive reactions if the hearer takes this accusation personally and, further, lacks the capacity or resources necessary to distance him or herself from the genocide in other ways than denial or challenge. 
However, I believe that a further aspect of testimonial incompetence cultivated by genocide denialism is the inability to distinguish an accusation, for example, from a personal report. In the latter case, such defensive responses are not only unwarranted but also fail to make sense. ${ }^{11}$ Moreover, genocide denialism likely cultivates testimonial incompetence due to the framing of the Armenian genocide as an ongoing debate reserved for historians as well as a purely legal matter, thereby distorting and deflecting from the social-moral dimension of genocide testimony. It bans such conversations from the social-moral sphere and refers it to the realm of supposedly neutral and objective legal and historical fact-finding. This likely disposes hearers to treat testimony on genocide merely as a piece of potential evidence for a legally and historically disputable fact. However, particularly in conversations such as the ones cited above, the speaker reports on a morally important personal and social matter and trusts the hearer to acknowledge this intention, instead of being subjected to unapt scrutiny. In such personal testimony, the testifier herself vouches for its truth, and it would be misguiding to assign it mere probative value that needs to be corroborated by further pieces of evidence. In fact, it would not only be misguiding; if we understand such reports as an invitation to trust both in the truth of its content and in the speaker herself in terms of her personal (in the case at hand, intergenerational) experience of that propositional content, it 'raises the stakes of a report, and disbelief in the report is subsequently a stronger repudiation than it is for tellings generally’ (Herbert 2019, 18). These stakes are captured by Der-Meguerditchian when she complains: "How is one to bear the fact that someone so young and warm and friendly says she doesn't know if something that shaped and defines one's whole existence happened or not?”

The seriousness of these stakes indicates that certain kinds and conditions of testimony require bringing to bear other forms of assertion/expression and more complex 
ways of their evaluation. Surely, testimony is, like perception and reason, a crucial but fallible epistemic source, hence it ought to be practiced critically. However, there is a substantial difference in critically assessing testimony between a broad view of testimony as 'all kinds of tellings' including everyday instances of informing, and, more specifically, testimony involving personal information or experiences of injustice. People do not have a particular interest and stake when telling people what time it is or giving road directions, but they do so when sharing personal experiences and information. Moreover, if someone testifies to genocide, one seems to be not merely stating a fact, but expressing a moral judgment. Now, the encounters mentioned at the outset of this section might not seem like evident cases of moral testimony: Der-Meguerditchian is not stating, "what my grandparents experienced was morally wrong and moreover, constituted genocide”, inviting the hearer to acquire a trust-based moral belief about these historical events. Rather, her report presupposes shared moral understanding. Presupposing that they have a shared normative background, a testimonially competent hearer arguably would understand, or at the least try to understand, that the primary intention of the speaker was not to make a baseless accusation or invite the hearer to debate the concept of genocide, but rather to seek proper recognition of the personal report offered. At least, this is what the speaker trusts the hearer to do. Systematic disappointment or betrayal of such trust, then, can ultimately give rise to testimonial smothering. ${ }^{12}$

This suggests that testimony can put particular moral demands on the epistemic agency of speakers and hearers. ${ }^{13}$ While speakers need to weigh the risk of testimony as regards the reproduction of hostilities and prejudice towards their community that perpetuate their oppression, hearers need to indicate testimonial competence to would-be speakers in order not to subject them to testimonial smothering, thereby coercing them to act in ways that further their own oppression. In the final section, I explore some of the 
distinct harms of such testimonial oppression perpetrated particularly against members of the victim group.

\section{V - The Distinct (Epistemic) Harms of Testimonial Oppression}

Conditions of genocide denialism legitimize distrust and default scepticism towards testimony on genocide, which systematically deprives testifiers of epistemic recognition. We can distinguish two dimensions and mechanisms of such deprivation, or epistemic misrecognition: on the one hand, genocide denialism discredits the victim group as a whole by attributing various negative characteristics to the group. This is done, for example, by systematically portraying Armenians as suggestible, as supposedly adopting inadequate hermeneutical resources (i.e. genocide) to interpret their past, because their experiences and memories have been distorted through 'a myth of genocide' in order to legitimize Armenian nationalism and imperial power play (e.g., Altanian 2017, 29-32). It is not incidental that the denigration or general social and moral misrecognition of a particular group gives rise to a whole set of accompanying prejudices, including misrecognition of their status as knowers. This makes for a very systematic and persistent social injustice, oppressing them on various dimensions of social activity, such as economic, educational, professional, legal, political, moral, and epistemic activity (Fricker 2007, 27). Accordingly, practices of genocide denial can be based on such identity ('tracker') prejudice and therefore systematically target particular knowers, but not necessarily.

On the other hand, genocide denialism entails factual and normative distortions of the subject matter of genocide. Here, epistemic contributions are rejected insofar as they threaten the dominant and dominating understanding of the genocide and thereby the whole belief system that supports this understanding. Thus, beyond misrecognizing social identities, genocide denialism misrecognizes and targets particular information. ${ }^{14}$ Note 
that this second dimension makes it likely that all members of society are coerced to silence themselves on genocide. In the case of the Armenian genocide, which is a national security issue in Turkey, the AKP government, especially since 2015, has been cracking down on anyone publicly criticizing the current power structures and defending minority interests and rights, including the right to genocide recognition. The recent decision of the Turkish government to establish 'a new autonomous and civil institution' in order 'to respond to the accusations of genocide and to develop a strategy [to counter them] ${ }^{15}$ further demonstrates that there is no intention to back down from the state-sanctioned policy of genocide denialism. This decision comes a few years after the Turkish Parliament's constitutional committee passed a bill banning the use of the term Armenian genocide on July 21, 2017. ${ }^{16}$ While this ultimately epistemically harms all members of society in particular ways, the way in which the subject matter of genocide is framed in this societal context has distinct implications for members of the former victim group. The subject matter is polarized to the extent that any admission of injustice and accountability would amount to treason against the Turkish state and to promoting the disunity of the Turkish nation. Hence, because the two dimensions of genocide denialism are not separable, but both constitute the discursive structure of genocide denialism, even non-members fighting for genocide recognition might feed into the oppression of historically marginalized members of the former victim group.

In addition, there is a mutually reinforcing loop between the two dimensions: Under conditions of pervasive ignorance about genocide, the fragile testimony of thusly marginalized will appear implausible to the testimonially incompetent hearer, which may ultimately feed into and perpetuate distrust. On the other hand, hearers with prior distrust can seek corroboration of such distrust. As Jones has pointed out, distrust 
puts in place a suspicious cognitive set that colors how we will interpret the words of another. It leads us to look for signs of deception, irrationality, or incompetence and thus leads us to seek out evidence of inconsistencies, to magnify those we suppose ourselves to have found, and to focus on them in our assessment of the story as a whole. (Jones 2002, 159)

For the remainder of this section, I shall briefly elaborate how the moral notion of recognition can be epistemically relevant in such an immediate sense, distinctly harming members of the former victim group. For this purpose, I refer to Congdon's (2018) application of Honneth's threefold conception of recognition-based on love, respect, and esteem - to the epistemic realm. I shall only discuss the first two, since esteem is a non-egalitarian notion bound to individual achievement, which is not particularly relevant to my argument here.

Epistemic love refers to attention, encouragement, and patience given to potential knowers to develop their sense of epistemic trust and epistemic confidence. As Congdon $(2018,12)$ notes, 'the recipient of epistemic love is given a chance to view herself from the perspective of others as one whose epistemic neediness and social dependence is acknowledged as legitimate, or worth caring for'. Trust and empathy can play an important role here. Since epistemic love points to something we need a sufficient amount of in order to develop our epistemic capacities, thus pointing to a quantitative type of recognition (cf. Medina 2018), suffering epistemic neglect is particularly severe when it occurs persistently and systematically (cf. Fricker 2007, 29, 49-50). It can eventually lead to a loss of confidence in one's beliefs or general intellectual capacities and ultimately, a loss of knowledge. Epistemic confidence refers to a condition where epistemic agents can learn to rely on their cognitive capacities - e.g., if they have proven to be taken up well, or if they have been recognized as valuable contributors to testimonial exchange. Epistemic confidence can thereby support the development of certain intellectual virtues, 
such as 'intellectual courage, the virtue of not backing down in one's convictions too quickly in response to challenge' (Fricker 2007, 49). Intellectual self-trust is a more general (positive) attitude towards ourselves, or as Jones puts it, 'a stance that an agent takes towards her own cognitive methods and mechanisms, comprising both cognitive and affective elements, and revealed in the agent's perception of reasons to withhold or defer in her judgment on the basis of their deliverances’ (Jones 2012, 238). It manifests itself in confidence, 'in dispositions willingly to rely on the deliverances of one's methods and to assert what is believed on their basis, and in modulating self-reflection' (245). Retaining such intellectual self-trust-and respectively, epistemic confidence-can therefore be crucial for retaining agency as well as resisting epistemic injustice. ${ }^{17}$

Applying these implications of epistemic neglect to my case study reveals that persistent and systematic genocide denial can cause members of the former victim group to lose confidence in their beliefs (or reasons for their beliefs) about what happened to their ancestors, their ability to assess historical sources of evidence-including biographies, memoirs, and testimonies_-and to detect injustice. This would also render them unable to understand their present living conditions and the social relations that shape how they can navigate society, unable to understand the distress that goes along with being a member of the former victim group, the constant threats to their lives through dominating and oppressive institutions, and to understand properly the (intergenerationally) transmitted memories of trauma and vulnerability from their family and fellow group members. Ultimately, it can prevent them from re-asserting their identity and realizing their moral and political agency: from appropriately protesting their structurally inferior position. This makes evident that genocide denialism inherently connects both testimonial and hermeneutical injustice, as it involves both unjust constraints on their hermeneutical capacity to render their (historical) experiences 
intelligible to themselves and to others, and on their capacity to testify to past and present injustice, both of which are crucial for personhood and responsible, moral agency (e.g., Campbell 2003, 41-43). ${ }^{18}$

Another recognition failure relates to epistemic respect, that is, to 'respect someone qua knower irrespective of the differential strengths and weaknesses by which we typically judge knowers’ (Congdon 2018, 13). Epistemic respect means to regard one another as equals in the space of reasons, to acknowledge mutual answerability and hold each other responsible in the give and take of reasons. In turn, epistemic disrespect is 'a violation of the implicit normative promise that all knowers be subjected to the same basic standards of criticism within the space of reasons' (15). Genocide denialism subjects members of the former victim group to unwarranted standards of criticism due to certain background attitudes of prejudice and inflated distrust about the epistemic and moral integrity of people of the speaker's social type. To epistemically disrespect someone, then, means to stand towards them in a relationship of presumed distrust on morally culpable grounds. De-authorising and constructing identities of members of the former victim group as epistemically inferior, i.e., as inherently unreliable when it comes to the subject matter of genocide, epistemically disrespects speakers in a systematic way; they are not given equal standing in the practice of mutual reasoning.

Note that under conditions of genocide denialism, testimonial smothering is a potential threat: under such conditions, it is likely that speakers will be coerced to silence themselves. This does not imply that resistance to oppression is impossible and that everyone is unable to maintain their intellectual self-trust and epistemic confidence. However, identifying the potential threat and harms that an institutional practice of genocide denial engenders gives us a reason to acknowledge claims to genocide recognition as indeed acts of legitimate epistemic resistance to conditions of objectively 
unjust coercion. Such coercive power is deeply entrenched in the fibre of society and operates not only structurally but also in everyday personal interactions.

\section{VI - Conclusion}

This article presents a normative analysis of genocide denialism in its own right in order to identify it as an additional injustice against the (former) victim group. It does so by showing how genocide denialism, understood as an epistemically pernicious practice of ignorance, creates conditions that unjustly coerce testifiers to silence themselves. More specifically, genocide denialism meets the circumstances identified by Dotson (2011) that routinely give rise to a specific form of testimonial oppression: testimonial smothering. First, it renders the content of testimony (on genocide) unsafe and risky, insofar as it leads or contributes to the 'formation of false beliefs that can cause social, political, and/or material harm'—in the case at hand, e.g., the negative prejudice against Armenians as treacherous agitators and provocateurs. Secondly, it cultivates substantive ignorance in an audience, who will thereby demonstrate testimonial incompetence to the speaker with respect to the content of the testimony. This is because the dominant and dominating agents of genocide denialism authorize, justify and impose a set of beliefs and understandings that constitute pernicious reliable ignorance about genocide. I illustrated this by reference to communicative encounters in which a descendant of genocide survivors offers genocide testimony in the form of a personal report, which is met with unapt responses of resistance and (pseudo-) scepticism on behalf of hearers due to various cognitive mechanisms inculcated through conditions of pervasive ignorance about genocide. Genocide denialism thereby undermines trust relations crucial for testimony and systematically deprives potential testifiers of valuable epistemic recognition. Systematic deprivation of such epistemic recognition can undermine their capacities of (self-) comprehension and reasoning, and of making 
relevant epistemic contributions in order to actively resist their oppression and seek social change. Ultimately, it coerces them to act in ways that further their own oppression.

A proper normative analysis of genocide denialism requires acknowledging the interplay of institutional, structural denialism and individual, interpersonal denial. Genocide denialism gets its persuasiveness from the argumentative and narrative, factual and normative distortions whereby perpetrators of genocide have historically legitimized their actions and policies, subsequently nourishing ongoing denialism and therefore, ongoing epistemic harm towards the former victim group.

\section{Acknowledgements}

I am grateful for the feedback received on earlier versions of this article from participants at the workshop 'Epistemic Injustice in the Aftermath of Collective Wrongdoing' (University of Bern, December 2019), as well as the Covid lockdown-induced virtual work-in-progress meetings with colleagues, in particular, Stephanie Deig, Tanja Rechnitzer, and Kathrin von Allmen. I am especially grateful for the detailed written comments and suggestions by Gaile Pohlhaus, Nadja El Kassar and Deborah Mühlebach, a then anonymous reviewer. This article is based on my doctoral research, which was supported by a Swiss National Science Foundation (SNSF) Doc.CH Career Grant, Project Number 175317.

\section{Notes}

1 See e.g. Altanian (2017) and (2019) for earlier versions of the argument.

2 Referring to the scholarly consensus that oppression comes out of unjust social and political institutions. (Cudd 2006, 20)

3 This condition is likely owed to Cudd's account of social groups as 'a collection of persons who share (or would share under similar circumstances) a set of social constraints on action' (2006, 44), which fits both voluntary and nonvoluntary social groups. According to Cudd, '[o]ne of the important differences between voluntary and nonvoluntary social groups is that one need not recognize that one is a member of a particular nonvoluntary social group to be a member. One simply needs objectively to face the constraints that other members face, 
whether or not one recognizes them as patterned constraints that one shares.' (Ibid., 45) Hence one can belong to a social group nonvoluntarily, regardless of whether one recognizes said oppressive harms, and whether a social group exists is determined primarily by external conditions that are objectively oppressive.

4 Dotson considers testimonial oppressions as practices of silencing of which she identifies two forms: testimonial quieting and testimonial smothering. While in testimonial smothering, speakers are coerced to silence themselves due to circumstances brought about by socially unjust background conditions, testimonial quieting refers to the failure of an audience to identify a speaker as a knower due to 'controlling images' (false, negative stereotypes or prejudices) whereby a specific social identity is rendered epistemically disadvantaged or inferior. This resembles Fricker's (2007, 30-41) central case of discriminatory, systematic testimonial injustice. Both forms are relevant to the analysis of genocide denialism, though testimonial smothering enables me to highlight the complexity of the circumstances brought about by genocide denialism, which render potential hearers testimonially incompetent in various ways, including possession of negative epistemic identity prejudice.

5 For the purpose of this article, I will not provide a detailed positive account of what such testimonial competence and the respective duties and responsibilities of hearers entail. The primary focus is rather on the background conditions of pervasive ignorance that likely cultivate testimonial incompetence and the harms that resultant silencing brings about for potential testifiers.

6 Note that these are examples of denialism in the aftermath of the genocide, as well as during and after Turkish nation state building. For a more detailed and succinct historical discussion of the Armenian genocide and the genocidal ideology that sought to legitimize it, see Oranl1 (forthcoming). This also makes evident the historical continuation of said portrayal of Armenians from prior to after the genocide.

7 Website of Turkey's Ministry of Foreign Affairs (MFA). 2020. “The unofficial translation of the message of H.E. President Recep Tayyip Erdoğan, the then Prime Minister of the 
Republic of Turkey, on the events of 1915 (23 April 2014).” Accessed September 1, 2020. http://www.mfa.gov.tr/turkish-prime-minister-mr_-recep-tayyip-erdo\%C4\%9Fan-publisheda-message-on-the-events-of-1915_-23-april-2014.en.mfa

8 Website of the MFA. 2020. "The Events of 1915 and the Turkish-Armenian Controversy over History: An Overview.” Accessed September 1, 2020. http://www.mfa.gov.tr/theevents-of-1915-and-the-turkish-armenian-controversy-over-history_-an-overview.en.mfa

9 Note that these encounters serve to illustrate a mechanism of testimonial failure I wish to highlight. My aim is not to thereby argue that Armenians also encounter testimonial smothering within the context of Germany, where these particular encounters took place (though they still present instances of silencing).

10 I refer to 'Turks' as socially dominant in the context of Turkey, in which my analysis of testimonial oppression is embedded. That being said, depending on the context of the encounter (including existing power relations) and the persistency of genocide denial, it might be harmful in other ways than constitute testimonial oppression.

11 Cassie Herbert (2019) makes a similar point in the context of the \#Metoo movement, arguing that it was 'centrally and powerfully about survivors issuing truth-claims about first-personal experiences of sexual violation' (18), hence reports, rather than a movement of accusations. Accusations are speech acts that aim to hold someone accountable for their wrongdoing, which would require naming the perpetrator and seeking some form of sanction for his norm violation. As such, they are perpetrator rather than victim-survivor centred. Reports, on the other hand, are an 'invitation to trust, both in terms of trusting that the content of the account is true and in terms of trusting in the speaker themself in terms of their first-personal experience of that propositional content' (Ibid.). I thank Gaile Pohlhaus for bringing Herbert's superb article to my attention.

12 In one of her many valuable comments on my article, Gaile Pohlhaus has related this to Wittgensteinian language games in an enlightening way: The sense of the testimony is in part dictated by the rules of the game-if you are not participating in the same language game, you will not make sense to one another. Against this background, in contexts of 
oppression, one can be coercively co-opted into a language game one was not intending to play: In the case of detailing one's family background, to receive this information as an accusation distorts the information and so prevents the sense of that information from circulating as intended.

13 It is subject to further inquiry whether hearers, in light of this, are failing morally or epistemically, or one in virtue of the other when engaging in such practices of silencing.

14 However, the subject matter of genocide takes on a distinct role in the former victim group's self-understanding, such that its misrecognition is inherently connected to the misrecognition of the group itself. This is because genocide has crucial explanatory value and relevance for the former victim group in terms of shared historical experience and collective memory, as well as for understanding present-day experiences of oppression (see e.g. Altanian 2019, 156-159). Weekly, June 24, 2020. https://armenianweekly.com/2020/06/24/statement-of-dr-tanerakcam-on-the-recent-decision-of-turkish-government/

16 “Turkish Parliament Committee Bans Mentioning of Armenian Genocide in Parliament”, The Armenian Weekly, July 24, 2017. https://armenianweekly.com/2017/07/24/turkishparliament-committee-bans-mentioning-of-armenian-genocide-in-parliament/

17 For a detailed discussion of the role of intellectual self-trust for dealing with epistemic injustice, see El Kassar 2020; El Kassar (forthcoming).

18 I engage in a more thorough analysis of how testimonial and hermeneutical injustice are inherently connected in my upcoming book, The Epistemic Injustice of Genocide Denialism (Manuscript in preparation).

\section{References}

Alcoff, L. M. 2007. “Epistemologies of Ignorance: Three Types.” In Race and Epistemologies of Ignorance, edited by N. Tuana and S. Sullivan, 39-58. Albany: SUNY Press. 
Altanian, M. 2017. “Archives against Genocide Denialism? Challenges to the Use of Archives in Turkish-Armenian Reconciliation.” Working Paper series, 1. Basel: Swisspeace. URL:

https://www.swisspeace.ch/assets/publications/downloads/WorkingPapers/ee36f55d94/Archives-against-Genocide-Denialism-Working-Paper2017-swisspeace-melanie_altanian.pdf

Altanian, M. 2019. “Genocide Denialism as an Intergenerational Injustice.” In Intergenerational Equity: Environmental and Cultural Concerns, World Trade Institute Advanced Studies: Vol. 4, edited by T. Cottier, S. Lalani, and C. Siziba, 151-162. Leiden: Brill. DOI: 10.1163/9789004388000_011

Aybak, T. 2016. “Geopolitics of Denial: Turkish State’s ‘Armenian Problem’.” Journal of Balkan and Near Eastern Studies, 18 (2): 125-144. DOI: 10.1080/19448953.2016.1141582

Campbell, S. 2003. Relational Remembering: Rethinking the Memory Wars. Lanham, MD: Rowman \& Littlefield.

Congdon, M. 2018. “'Knower’ as an Ethical Concept: From Epistemic Agency to Mutual Recognition.” Feminist Philosophy Quarterly, 4 (4:2). DOI: 10.5206/fpq/2018.4.6228

Crenshaw, K. 1991. "Mapping the Margins: Intersectionality, Identity Politics, and Violence Against Women of Color.” Stanford Law Review 43: 1241-1299.

Cudd, A. 2006. Analyzing Oppression. Oxford: Oxford University Press.

Der-Meguerditchian, S. 2011. “AFERIM YAVRUM: Little Gestures of Cooperation.” Exhibition Catalogue. Istanbul: BM Suma Contemporary Art Center. URL: https://issuu.com/silvina.der.meguerditchian/docs/aferim_yavrum_print_final_v ersion_light

Dormandy, K. 2020. “Exploitative Epistemic Trust.” In Trust in Epistemology, edited by K. Dormandy, 241-264. New York: Routledge.

Dotson, K. 2011. “Tracking Epistemic Violence, Tracking Practices of Silencing.” Hypatia, 26 (2): 236-257. DOI: 10.1111/j.1527-2001.2011.01177.x

El Kassar, N. 2020. "The Place of Intellectual Self-Trust in Theories of Epistemic Advantages.” Journal of Social Philosophy 51 (1): 7-26.

El Kassar, N. Forthcoming. "The Powers of Individual and Collective Intellectual SelfTrust in Dealing with Epistemic Injustice.” Social Epistemology: A Journal of Knowledge, Culture and Policy. 
Fricker, M. 2007. Epistemic Injustice: Power and the Ethics of Knowing. Oxford: Oxford University Press.

Fricker, M. 2015. “Epistemic Contribution as a Central Human Capability.” In The Equal Society: Essays on Equality in Theory and Practice, edited by G. Hull, 73-90. Lanham, MD: Lexington Books.

Harvin, C. B. 1996. “Conversations I Can’t Have.” The Progressive Woman’s Quarterly 5 (2): 15-16. URL:

https://www.ontheissuesmagazine.com/pdfs/1996Spring_vol5.pdf

Herbert, C. 2019. “The Speech Acts of \#Metoo.” APA Newsletter on Feminism and Philosophy, 19 (1): 16-20. URL:

https://cdn.ymaws.com/www.apaonline.org/resource/collection/D03EBDAB82D7-4B28-B897-C050FDC1ACB4/FeminismV19n1.pdf

Jones, K. 2002. “The Politics of Credibility.” In A Mind of One's Own: Feminist Essays on Reason and Objectivity (2nd ed.), edited by L. M. Antony and C. E. Witt, 154-176. Boulder, Colo.: Westview Press.

Jones, K. 2012. “The Politics of Intellectual Self-trust.” Social Epistemology, 26 (2): 237-251, DOI: 10.1080/02691728.2011.652215

Karlsson, M. 2015. “Cultures of Denial: Comparing Holocaust and Armenian Genocide Denial.” PhD diss., Lund University.

Medina, J. 2013. The Epistemology of Resistance: Gender and Racial Oppression, Epistemic Injustice, and Resistant Imaginations. Oxford: Oxford University Press.

Medina, J. 2018. “Misrecognition and Epistemic Injustice.” Feminist Philosophy Quarterly, 4 (4:1). DOI: 10.5206/fpq/2018.4.6233

Oranl1, I. Forthcoming. "Epistemic Injustice from Afar: Rethinking the Denial of Armenian Genocide.” Social Epistemology: A Journal of Knowledge, Culture and Policy.

Pauer-Studer, H. and J. D. V. 2011. “Distortions of Normativity.” Ethical Theory and Moral Practice, 14 (3): 329-356. DOI: 10.1007/s10677-010-9246-7

Pohlhaus Jr., G. 2012. "Relational Knowing and Epistemic Injustice: Toward a Theory of Willful Hermeneutical Ignorance.” Hypatia, 27 (4): 715-735. DOI: 10.1111/j.1527-2001.2011.01222.x 
Theriault, H. C. 2009. “Genocide, Denial, and Domination: Armenian-Turkish

Relations from Conflict Resolution to Just Transformation.” Journal of African Conflicts and Peace Studies, 1 (2): 82-96. DOI: 10.5038/2325-484X.1.2.5

Ulgen, F. 2010. "Reading Mustafa Kemal Atatürk on the Armenian Genocide of 1915.” Patterns of Prejudice, 44 (4): 369-391. DOI: 10.1080/0031322X.2010.510719 